Tropical Journal of Pharmaceutical Research June 2014; 13 (6): 889-894

ISSN: $1596-5996$ (print); 1596-9827 (electronic)

(C) Pharmacotherapy Group, Faculty of Pharmacy, University of Benin, Benin City, 300001 Nigeria.

All rights reserved.

Available online at http://www.tjpr.org

Original Research Article

http://dx.doi.org/10.4314/tjpr.v13i6.9

\title{
Effect of Interaction between Polymorphisms in Insulin Receptor Substrate Genes in Type 2 Diabetes Mellitus Patients with Severe/Acute Hyperglycemia
}

\begin{abstract}
Hasniza Zaman Huri ${ }^{1,2 *}$, Mohd Makmor-Bakry ${ }^{3}$, Rosnani Hashim ${ }^{4}$, Norlaila Mustafa ${ }^{5}$ and Wan Zurinah Wan Ngah $^{6}$

${ }^{1}$ Department of Pharmacy, Faculty of Medicine, University of Malaya, 50603 Kuala Lumpur, Malaysia, ${ }^{2}$ Clinical Investigation Centre, 13th Floor, Main Tower University of Malaya Medical Centre, 59100 Lembah Pantai, Kuala Lumpur, Malaysia, ${ }^{3}$ Faculty of Pharmacy, Universiti Kebangsaan Malaysia, Kuala Lumpur, Malaysia, ${ }^{4}$ Faculty of Pharmacy, Cyberjaya University College of Medical Sciences Cyberjaya, Malaysia, ${ }^{5}$ Department of Medicine, Faculty of Medicine, Universiti Kebangsaan Malaysia, Kuala Lumpur, Malaysia, ${ }^{6}$ Department of Biochemistry, Faculty of Medicine, Universiti Kebangsaan Malaysia, Kuala Lumpur, Malaysia.
\end{abstract}

*For correspondence: Email: hasnizazh@um.edu.my, hasnizazh@ummc.edu.my; Tel: +603 79676659

Received: 15 October 2013

Revised accepted: 21 March 2014

\begin{abstract}
Purpose: To investigate whether there are interactions between insulin receptor substrate 1 (IRS1) and insulin receptor substrate 2 (IRS2) that are associated with increased insulin resistance during such episodes.

Methods: Testing Haplotype EffectS in Association Studies (THESIAS) software was used to investigate allelic and haplotype interactions between the polymorphisms in 156 T2DM patients with severe or acute hyperglycemia.

Results: Binary analysis showed there were significant differences in the haplotype frequencies for the IRS1 and IRS2 polymorphisms based on the insulin resistance status. Nevertheless, estimation of haplotype effects by equality analysis showed no significant interactions (likelihood ratio tests: all $p$ > 0.05) in increased insulin resistance in T2DM patients with severe/acute hyperglycemia.

Conclusion: There are no interactions between IRS1 rs1801278 (p.Gly972Arg) and IRS2 rs1805097 (p.Gly1057Asp) polymorphisms that would affect insulin resistance in T2DM patients with severe/acute hyperglycemia.
\end{abstract}

Keywords: Insulin receptor substrate, Proteins, Insulin resistance, Diabetes mellitus, Hyperglycemia, Haplotype, Genetic polymorphism

Tropical Journal of Pharmaceutical Research is indexed by Science Citation Index (SciSearch), Scopus, International Pharmaceutical Abstract, Chemical Abstracts, Embase, Index Copernicus, EBSCO, African Index Medicus, JournalSeek, Journal Citation Reports/Science Edition, Directory of Open Access Journals (DOAJ), African Journal Online, Bioline International, Open-J-Gate and Pharmacy Abstracts

\section{INTRODUCTION}

The hormone insulin is essential for the metabolism of glucose and lipids. Insulin receptor substrate (IRS), an intermediate in insulin signaling, plays an important role in the basic functions of cell growth and metabolism [1,2]. Of the four genes in the IRS system, only IRS1 and IRS2 are involved in glucose metabolism [2]. The
IRS1 and IRS2 genes are responsible for glucose production by the liver, glucose uptake by skeletal muscle and adipose tissue, and insulin production by beta cells in the pancreas [2]. IRS1 functions in the skeletal muscle, while the role of IRS2 is mainly to regulate hepatic insulin action as well as pancreatic beta cell development and survival [2]. Defects in postreceptor insulin signaling are the main reasons 
for insulin resistance in target tissues that influence glycemic control [3]. In particular, these defects are displayed by the specific inhibition of the PI3K/Akt signaling pathways associated with positive insulin action on glucose and lipid metabolism [4].

IRS system gene polymorphisms are associated with insulin resistance [5]. The rs1801278 (p.Gly972Arg) polymorphism in IRS1 reduces tyrosine phosphorylation by more than $60 \%$ and acts as a competitive inhibitor of insulin receptor and insulin-like growth factor receptor 1 autophosphorylation [5]. Moreover, a previous study has described an association between rs1801278 and increased insulin resistance in patients during episodes of severe/acute hyperglycemia in type 2 diabetes mellitus (T2DM) patients [6]. However, the possibility of interaction between IRS1 and IRS2 gene polymorphisms in increased insulin resistance in T2DM patients with severe/acute hyperglycemia has not been investigated. In this study, we investigated the potential allelic and haplotype interactions between the IRS1 rs1801278 and the IRS2 rs1805097 polymorphisms and whether these interactions affected insulin resistance in type 2 diabetes patients with severe/acute hyperglycemia.

\section{EXPERIMENTAL}

\section{Patient recruitment}

Patients were recruited from all medical wards at the teaching hospital of the National University of Malaysia (UKMMC) and were screened for eligibility to participate in the study. The study complied with the Declaration of Helsinki, it was approved by the Ethics Committee of UKMMC (FPP-282-2008), and all participants gave their written, informed consent. The sample size calculation was based on the previous study [6].

For inclusion, the subjects had to meet the following specifications: blood glucose level > $13.9 \mathrm{mmol} / \mathrm{L}$; severe hyperglycemia [7] or glucose > $15 \mathrm{mmol} / \mathrm{L}$; acute hyperglycemia upon admission [8]; over 30 years old; only used insulin during hospitalization. Subjects were excluded if they met any of the following criteria: used oral hypoglycemic agents during hospitalization; were pregnant; were unable or unwilling to give informed consent; were critically-ill or exhibited medical conditions that were likely to limit life expectancy or required extensive medical treatment.

Ten-milliliter venous blood samples were taken for genetic analysis from the 156 T2DM patients who fulfilled the inclusion criteria.

\section{Measurement of insulin resistance}

Calculation of the insulin resistance index was based on the concentrations of fasting plasma glucose and insulin, according to the homeostasis model assessment (HOMA) formula [9]. The venous blood for baseline measurement of plasma glucose and plasma insulin was collected after an overnight fast, when both values are known to be at a steady-state [10]. The cut-off point on the HOMA index to indicate worsening insulin resistance was 2.7 , which was obtained from a receiver operating characteristic curve with a sensitivity of $97.4 \%$ and a value of 0 $\%$ for [1-specificity].

\section{Genetic analysis}

Genomic DNA was obtained from whole blood using a Wizard® Genomic DNA Isolation kit (Promega, Madison, WI). Polymorphisms in the IRS1 (rs1801278; p.Gly972Arg) and IRS2 (rs1805097; p.Gly1057Asp) genes were genotyped by PCR-restriction fragment length polymorphism analysis, following modification and optimization of previously described methods [11,12]. The rs1801278 and rs1805097 polymorphisms were detected by restriction digestion with BstNI and Haell, respectively.

\section{Hardy-Weinberg equilibrium (HWE) test}

The validity of the association study was tested by calculating HWE using Testing Haplotype EffectS in Association Studies (THESIAS) software [13].

\section{Allele and haplotype analysis}

Allele and haplotype analyses were carried out using THESIAS software (14). This program is based on the maximum likelihood model [14] and is related to the stochastic expectation and maximization algorithm [15]. Thesias allows simultaneous estimation of haplotype frequencies and their relationship with the phenotype of interest.

In this study, we performed both null and binary analyses. Null analysis refers to the probable haplotype frequencies, based on the HWE test. The analysis was divided into two assumptions: "no linkage disequilibrium (LD)" and "with LD". LD is defined as the effects of gene variation that may be caused by an allele or genotype that is located near the locus of the gene under study [16]. Binary analysis refers to the classification of haplotype frequencies based on phenotypic features-in this case, insulin resistance status. In estimating haplotype effects, the estimated 
regression parameters describe the relationship between haplotype and phenotype in comparison to the most common haplotype. Haplotype 1 was the most common haplotype, and often corresponded to the intercept point on the regression model. Haplotype 2 was the second most frequent haplotype, followed by haplotype 3 , etc. Estimations of haplotype effects were expressed as the odds ratio and were compared with the reference (haplotype 1/intercept) with 95 $\%$ confidence intervals. With further analysis using equality tests, we sought to determine whether there was an interaction between haplotypes of the IRS1 and IRS2 polymorphisms. Thus, we assumed that the IRS1 allele, when carried by the IRS2 haplotype, was associated with insulin resistance. This means that the effect of haplotype 2 ( $\beta 2$ ) was similar to the effect of haplotype $4(\beta 4)$. Therefore, the null hypothesis tested was $\mathrm{HO}: \beta_{2}=\beta_{4}$. This was also applied to the other haplotypes; the other null hypotheses tested were $\mathrm{HO}: \beta_{1}=\beta_{3} ; \mathrm{HO}: \beta_{2}=\beta_{1}$; and $\mathrm{HO}: \beta_{4}=$ $\beta_{3}$. Null hypotheses were tested using the likelihood ratio test (LRT). In this analysis, the haplotype interaction effects were assessed by comparing the log-likelihood of the testedhypotheses model with the log-likelihood of the full model. LRT test to assess the haplotypephenotype relationship was equal to twice the difference between the logs. Statistical significance was assessed by chi-squared test. A $p$-value $<0.05$ was considered significant.

\section{RESULTS}

In this study, we genotyped the IRS1 (rs1801278; p.Gly972Arg) and IRS2 (rs1805097; p.Gly1057Asp) gene polymorphisms in 156 T2DM patients with severe/acute hyperglycemia. For rs 1801278 , the frequency of allele A was 3.5 $\%$ and that of allele $G$ was $96.5 \%$. The frequency of genotype G/A was $7.1 \%$ and $G / G$ was $92.9 \%$. For rs1805097, the frequency of allele $A$ was $41.7 \%$ and that of allele $G$ was 58.3 $\%$. The genotype frequencies were A/A (17.9\%), G/A (47.5\%), and G/G (34.6\%). There was a significant association between the IRS1 polymorphism rs1801278 and insulin resistance status in the T2DM patients $\left(x^{2}=5.19, p=\right.$ 0.023 ), but no association between the IRS2 polymorphism rs1805097 and insulin resistance status $\left(X^{2}=0.69, p=0.406\right)$.

\section{HWE testing}

The IRS1 rs1801278 and IRS2 rs1805097 polymorphisms were both in HWE $(p=0.6481$ and $p=0.7627$, respectively), which confirmed the validity of our subsequent analyses.

\section{Calculation of haplotype frequencies}

Haplotype frequencies of the IRS1 rs1801278 and the IRS2 rs1805097 polymorphisms were calculated under the assumption of "no LD" and "with LD" (Table 1). There were no significant differences between them.

Table 1: Haplotype frequencies under the assumptions of "no LD" and "with LD"

\begin{tabular}{lccc}
\hline & $\begin{array}{c}\text { Haplotype } \\
\text { (IRS1, IRS2) }\end{array}$ & $\begin{array}{c}\text { No LD } \\
\text { (frequency) }\end{array}$ & $\begin{array}{c}\text { With LD } \\
\text { (frequency } \pm \text { SD) }\end{array}$ \\
\hline Haplotype 1 & GG & 0.5628 & 0.5579 \\
Haplotype 2 & GA & 0.4020 & $0.4069 \pm 0.0307$ \\
Haplotype 3 & AG & 0.0206 & $0.0254 \pm 0.0096$ \\
Haplotype 4 & AA & 0.0146 & $0.0098 \pm 0.0065$ \\
\hline
\end{tabular}

Haplotype 1 was the reference haplotype; $L D=$ linkage disequilibrium; $S D=$ standard deviation

Second, we analyzed whether the haplotypes were associated with insulin resistance during the severe/acute hyperglycemia phase in T2DM patients. Haplotype frequencies were calculated by binary analysis based on the subjects' insulin resistance status ("sensitive" or "resistant") (Table 2). There were significant differences in the haplotype frequencies based on the insulin resistance status $\left(x^{2}=26.5, p=0.0001\right)$. The estimate of the intercept point for binary analysis of the logistic model was 0.5324. The loglikelihood of the data (without the effect of haplotype) was $-289.06(\mathrm{df}=1)$.

Table 2: Haplotype frequencies based on insulin resistance status

\begin{tabular}{lccc}
\hline & $\begin{array}{c}\text { Haplotype } \\
\text { (IRS1, IRS2) }\end{array}$ & $\begin{array}{c}\text { Insulin } \\
\text { sensitive } \\
\text { (frequency) }\end{array}$ & $\begin{array}{c}\text { Insulin } \\
\text { resistant } \\
\text { (frequency) }\end{array}$ \\
\hline Haplotype 1 & GG & 0.5414 & 0.5632 \\
Haplotype 2 & GA & 0.3836 & 0.4152 \\
Haplotype 3 & AG & 0.0586 & 0.0143 \\
Haplotype 4 & AA & 0.0164 & 0.0073 \\
\hline
\end{tabular}

\section{Estimation of haplotype effects and equality analysis}

Equality analysis was then performed based on the other haplotype background. Comparison of the log-likelihood of the tested-hypotheses model with the log-likelihood of the full model showed that haplotype/allelic interaction between the IRS1 and IRS2 polymorphisms was not associated with insulin resistance during the severe/acute hyperglycemia phase (LRT; all pvalues > 0.05; Tables $3-4$ ). 
Table 3: Measurement of haplotype effects and haplotype effects based on type of polymorphism (full model)

\begin{tabular}{llccc}
\hline & & \multicolumn{3}{c}{ Measurement of haplotype effects } \\
\cline { 3 - 5 } & & Estimate & Standard error & $t$-statistic \\
\hline $\begin{array}{l}\text { Haplotype 1 } \\
\text { (intercept) }\end{array}$ & GG & 0.5916 & 0.1514 & 3.9066 \\
\hline Haplotype 2 & GA & 0.0004 & 0.2711 & 0.0014 \\
& OR $=1.0004[0.5880-1.7021] ; p=0.998$ & \\
Haplotype 3 & AG & -0.1640 & 0.8491 & -1.9307 \\
& OR $=0.1941[0.0367-1.0251] ; p=0.050$ & \\
Haplotype 4 & AA & -0.8071 & 1.3179 & -0.6124 \\
& OR $=0.4462[0.0337-5.9056] ; p=0.540$ & \\
\hline
\end{tabular}

\section{Haplotype effects based on type of polymorphism (full model)}

Log likelihood $=-286.67(n=156)$

Conditional log-likelihood $=-86.42(\mathrm{df}=4)$

IRS1 rs1801278 (G/A)

Haplotype background $\quad-G \quad 1-3 \quad$ OR $=0.1941[0.0367-1.0252] ; p=0.053$

Haplotype background $\quad-A \quad 2-4 \quad$ OR $=0.04460[0.0311-6.4015] ; p=0.552$

Haplotype background $\quad$ G- $\quad 1-2 \quad$ OR $=1.0004[0.5880-1.7021] ; p=0.998$

Haplotype background $\quad$ A- $\quad 3-4 \quad$ OR $=2.2989[0.0875-60.4258] ; p=0.618$

OR, odds ratio with [95\% confidence interval]

Table 4: Interaction effects between haplotypes 1 and 3; haplotype 2 and 4; haplotype 1 and 2

Interaction effects between haplotypes 1 and 3

OR, odds ratio with [95\% confidence interval]. LRT: $x^{2}=3.86, p=0.050$.

Log-likelihood $=-288.6(n=156)$

Conditional log-likelihood $=-88.35(\mathrm{df}=3)$

IRS1 rs1801278 (G/A)

Haplotype background

Haplotype background

$-\mathrm{G} \quad 1-3 \quad \mathrm{OR}=1$

IRS2 rs1805097 (G/A)

Haplotype background

$-A \quad 2-4$

$\mathrm{OR}=0.2834[0.0199-4.0367] ; p=0.352$

Haplotype background

$\begin{array}{lll}\text { G- } & 1-2 & \text { OR }=1.1505[0.6898-1.9188] ; p=0.591 \\ \text { A- } & 3-4 & \text { OR }=0.3260[0.024-4.395] ; p=0.398\end{array}$

Interaction effects between haplotypes $\mathbf{2}$ and $\mathbf{4}$

OR, odds ratio with [95\% confidence interval]. LRT test: $\chi^{2}=0.26, p=0.975$.

Log-likelihood $=-286.82(n=156)$

Conditional log-likelihood $=-86.56(\mathrm{df}=3)$

IRS1 rs1801278 (G/A)

Haplotype background

Haplotype background

IRS2 rs1805097 (G/A)

Haplotype background

Haplotype background

$\begin{array}{lll}-\mathrm{G} & 1-3 & \mathrm{OR}=0.1763[0.0333-0.9320] ; p=0.040 \\ -\mathrm{A} & 2-4 & \mathrm{OR}=1 \\ \text { G- } & 1-2 & \mathrm{OR}=0.9619[0.5754-1.6077] ; p=0.882 \\ \text { A- } & 3-4 & \mathrm{OR}=5.4574[1.0640-27.9910] ; p=0.042\end{array}$

Interaction effects between haplotypes 1 and 2

OR, odds ratio with [95\% confidence interval]. LRT test: $\chi^{2}=0.00, p=0.975$.

Log likelihood $=-286.67(n=156)$

Conditional log-likelihood $=-86.42(\mathrm{df}=3)$

IRS1 rs1801278 (G/A)

Haplotype background

Haplotype background

-G $\quad 1-3$

$\mathrm{OR}=0.1973[0.0395-0.9867] ; p=0.050$

IRS2 rs1805097 (G/A)

$-A \quad 2-4$

$\mathrm{OR}=0.4318[0.0327-5.7008] ; p=0.524$

Haplotype background

G- $\quad 1-2$

$\mathrm{OR}=1$

Haplotype background

A- 3-4

$\mathrm{OR}=2.1886$ [0.0872-54.9266]; $p=0.634$ 


\section{DISCUSSION}

THESIAS software was used in this study to investigate the interaction between genetic polymorphisms of the IRS1 and IRS2 genes with the insulin resistance status in T2DM patients with severe/acute hyperglycemia. The haplotype frequencies in the null analysis were necessary to determine the basic haplotype structure that was derived from the polymorphisms under investigation, regardless of the phenotypic effects. This means that the frequencies given at this stage were not influenced by the insulin resistance status of the study population.

The haplotype frequencies shown were calculated as the product of matched allele frequencies. Not all haplotype frequencies were reported; only the corresponding haplotype that was compatible with the genotype data of at least one individual was stated. As the two frequencies did not differ significantly, it was assumed that there was no linkage disequilibrium. Occasionally, the occurrence of linkage disequilibrium can explain polymorphism interactions that would significantly affect phenotypic features. In this study, binary analysis showed a significant difference between the haplotype frequencies based on insulin resistance status.

Further equality analysis however failed to show any significant interactions between the alleles or haplotypes of the studied polymorphisms. This supports previous findings that only the IRS1 Gly972Arg polymorphism is associated with the insulin resistance status of T2DM patients with severe/acute hyperglycemia [6]. It is also consistent with the findings of Villuendas et al [17] who found no interaction between the IRS1 and IRS2 genes in relation to insulin resistance in people with polycystic ovary syndrome.

Our findings suggest that, although IRS1 and IRS2 function in the same system, they have different signaling specificities. This specificity may occur because of a unique sequence between amino acids 591 and 786 in the middle of IRS2 that interacts specifically with the kinase regulatory loop of the insulin receptor beta subunit [18]. This region is not present in IRS1. Differences in the kinetic energy of activation/deactivation, as well as the specificity of interaction with upstream effectors $[19,20]$ may also explain the differences.

\section{CONCLUSION}

In summary, we found no evidence for interactions between the IRS1 rs1801278 $\begin{array}{lll}\text { (p.Gly972Arg) and IRS2 rs1805097 } & \text { and }\end{array}$ (p.Gly1057Asp) polymorphisms that would affect the insulin resistance in T2DM patients with severe/acute hyperglycemia. Further studies are necessary to confirm these results and validate them in other populations.

\section{Limitation of the study}

This study focused on a specific study population; hence, it might not be possible to extrapolate these results to other races or countries.

\section{ACKNOWLEDGEMENT}

The authors would like to thank to the National University of Malaysia, University of Malaya, Malaysia, and the Ministry of Higher Education, Malaysia for financial and technical support.

\section{REFERENCES}

1. Dong XC, Park S, Lin X, Copps K, Yi X, White MF. IRS1 and IRS2 signaling is essential for hepatic glucose homeostasis and systemic growth. J Clin Invest 2006; 116(1): 101-114.

2. Sesti G, Federic $M$, Hribal $M L$, Lauro $D$, Sbraccia $P$, Lauro $R$. Defects of the insulin receptor substrate (IRS) system in human metabolic disorders. FASEB $J$ 2001; 15(12): 2099-2111.

3. Burgering BM, Coffer PJ. Protein kinase $B$ (c-Akt) in phosphatidylinositol-3-OH kinase signal transduction. Nature 1985; 376: 599-602.

4. Zhao L, Sun D, Cao F, Yin T, Wang $H$. Can insulin resistance be reversed by insulin therapy? Med. Hypotheses 2009; 72: 34-35.

5. Aileen JM, Edward PF, Ronald K. Human insulin receptor substrate-1 (IRS-polymorphism G972R causes IRS-1 to associate with the insulin receptor and inhibit receptor autophosphorylation. J. Biol. Chem 2005; 280(8): 6441-6446.

6. Huri HZ, Makmor-Bakry M, Hashim R, Mustafa N, Wan Ngah WZ. Optimisation of glycaemic control during episodes of severe/acute hyperglycaemia in patients with type 2 diabetes mellitus. Int. J. Clin. Pharm. doi: 2012; 10.1007/s11096-012-9682-7.

7. Inzucchi SE. Management of hyperglycemia in the hospital setting. New Engl. J. Med 2006; 355(18): 1903-911.

8. Marfella $R$, Verrazzo G, Acampora R. Glutathione reverses systemic hemodynamic changes induced by acute hyperglycemia in healthy subjects. Am. J. Physiol 1995; 268(6): E1167-173.

9. Matthews DR, Hosker JP, Rudenski AS, Naylor BA, Treacher DF, Turner RC. Homeostasis model assessment: insulin resistance and beta-cell function 
from fasting plasma glucose and insulin concentrations in man. Diabetologia 1985; 28: 412-9.

10. Muniyappa $R$, Lee $S$, Chen $H$, Quon MJ. Current approaches for assessing insulin sensitivity and resistance in vivo: advantages, limitations, and appropriate usage. Am. J. Physiol. Endocrinol. Metab 2008; 294: E15-E26.

11. Federici M, Petrone A, Porzio O. The Gly972--Arg IRS-1 variant is associated with type 1 diabetes in continental Italy. Diabetes 2003; 52(3): 887-90.

12. Fritsche $A$, Madaus $A$, Renn $W$. The prevalent Gly1057Asp polymorphism in the insulin receptor substrate-2 gene is not associated with impaired insulin secretion. J. Clin. Endocrinol. Metab 2001; 86: 4822-25.

13. Tregouet DA, Garelle V. A new JAVA interface implementation of THESIAS: Testing haplotype effects in association studies. Bioinformatics 2007; 23(8): 1038-1039.

14. Tregouet DA, Barbaux S, Escolano S, Tahri N, Golmard $J L$, Tiret L, Cambien F. Specific haplotypes of the $P$ selectin gene are associated with myocardial infarction. Hum. Mol. Genet 2002; 11(17): 20152023.

15. Tregouet DA, Tiret L. Cox proportional hazards survival regression in haplotype-based association analysis using the Stochastic-EM algorithm. Eur. J. Hum. Genet 2004; 12(11): 971-974.
16. Goldstein DB, Weale ME. Population genomics: linkage disequilibrium holds the key. Curr. Biol 2001; 11(14): R576-R579.

17. Villuendas G, Botella-Carretero JI, Roldan B, Sancho J, Escobar-Morreale HF, San Millàn JS. Polymorphisms in the insulin receptor substrate-1 (IRS1) gene and the insulin receptor substrate-2 (IRS2) gene influence glucose homeostasis and body mass index in women with polycystic ovary syndrome and nonhyperandrogenic controls. Human Reprod 2005; 20(11): 3184-3191.

18. Sawka-Verhelle D, Tartare-Deckert $S$, White MF, Van Obberghen E. Insulin receptor substrate-2 binds to the insulin receptor through its phosphotyrosinebinding domain and through a newly identified domain comprising amino acid 591-786. J. Biol. Chem 1996; 271(11): 5980-5983.

19. Giovannone B, Scaldaferri ML, Federici M., Porzio O, Lauro D, Fusco A, Sbraccia $P$, Borboni $P$, Lauro $R$, Sesti G. Insulin receptor substrate (IRS) transduction system: distinct and overlapping signaling potential. Diabetes Metab. Res. Rev 2000; 16(6): 434-441.

20. Shuppin GT, Pons S, Hugl S, Aiello LP, King GL, White MF, Rhodes CJ. A specific increased expression of insulin receptor substrate 2 in pancreatic beta-cell lines is involved in mediating serum-stimulated-cell growth. Diabetes 1998; 47(7): 1074-1085. 